Published in final edited form as:

J Am Chem Soc. 2022 January 12; 144(1): 80-85. doi:10.1021/jacs.1c11340.

\title{
An Enzymatic Platform for Primary Amination of 1-Aryl-2-alkyl Alkynes
}

\author{
Zhen Liu ${ }^{\dagger}$, , Zi-Yang Qin ${ }^{\dagger}$, , Ledong Zhu ${ }^{\ddagger}$, I, Soumitra V. Athavale ${ }^{\dagger}$, Arkajyoti Sengupta $^{\ddagger}$, \\ Zhi-Jun Jia $^{\dagger, \|}$, Marc Garcia-Borràs ${ }^{\#}$, K. N. Houk ${ }^{\ddagger}$, Frances H. Arnold ${ }^{\dagger}$ \\ tDivision of Chemistry and Chemical Engineering, California Institute of Technology, Pasadena, \\ California 91125, USA \\ ‡Department of Chemistry and Biochemistry, University of California, Los Angeles, California \\ 90095, USA \\ \#Institut de Química Computacional i Catàlisi and Departament de Química, Universitat de \\ Girona, 17003 Girona, Spain
}

\begin{abstract}
Propargyl amines are versatile synthetic intermediates with numerous applications in the pharmaceutical industry. An attractive strategy for efficient preparation of these compounds is nitrene propargylic $\mathrm{C}\left(\mathrm{sp}^{3}\right)-\mathrm{H}$ insertion. However, achieving this reaction with good chemo-, regio-, and enantioselective control has proven to be challenging. Here, we report an enzymatic platform for the enantioselective propargylic amination of alkynes using a hydroxylamine derivative as the nitrene precursor. Cytochrome P450 variant PA-G8 catalyzing this transformation was identified after eight rounds of directed evolution. A variety of 1-aryl-2-alkyl alkynes are accepted by PA-G8, including those bearing heteroaromatic rings. This biocatalytic process is
\end{abstract}

\footnotetext{
Corresponding Author: Marc Garcia-Borràs - Institut de Química Computacional i Catàlisi and Departament de Química, Universitat de Girona, 17003 Girona, Spain, marc.garcia@udg.edu; K. N. Houk - Department of Chemistry and Biochemistry, University of California, Los Angeles, California 90095, United States, houk@ chem.ucla.edu; Frances H. Arnold - Division of Chemistry and Chemical Engineering, California Institute of Technology, Pasadena, California 91125, United, States; frances@cheme.cal-tech.edu.

ICurrent Address: Environment Research Institute, Shandong University, Qingdao 266237, P.R. China.

"Current Address: Key Laboratory of Birth Defects and Related Diseases of Women and Children, Department of Pharmacy/ Evidence-Based Pharmacy Center, West China Second University Hospital, Sichuan University, Chengdu 610041, P. R. China; Department of Biopharmaceutics, West China School of Pharmacy, Sichuan University, Chengdu 610041, P. R. China.

$\S$ Author Contributions

These authors contributed equally.

Supporting Information

Materials, experimental methods, compound characterization data, computational methods, and supplementary data. These materials are available free of charge via the Internet at http://pubs.acs.org.

The authors declare no competing financial interest.

Publisher's Disclaimer: Disclaimer

This report was prepared as an account of work sponsored by an agency of the United States Government. Neither the United States Government nor any agency thereof, nor any of their employees, makes any warranty, express or implied, or assumes any legal liability or responsibility for the accuracy, completeness, or usefulness of any information, apparatus, product, or process disclosed, or represents that its use would not infringe on privately owned rights. Reference herein to any specific commercial product, process, or service by trade name, trademark, manufacturer, or otherwise does not necessarily constitute or imply its endorsement, recommendation, or favoring by the United States Government or any agency thereof. The views and opinions of the authors expressed herein do not necessarily state or reflect those of the United States Government or any agency thereof.
} 
efficient and selective (up to 2610 total turnover number (TTN) and $96 \%$ ee) and can be performed on preparative scale.

Propargyl amines are an important class of molecules in organic synthesis and medicinal chemistry. ${ }^{1-3}$ This motif is widely observed in many bioactive molecules, ${ }^{2,3}$ such as drugs and their analogs (Scheme 1a). The functional group combination of an alkyne and an amine also makes them versatile synthetic intermediates toward complex structures. ${ }^{1,4}$ Popular methods to prepare propargyl amines include propargylic substitution with nitrogen nucleophiles, reductive amination of alkynyl ketones, and imine alkynylation. 1,5 While efficient, these methods require the use of hazardous organometallic reagents or prefunctionalization of the alkyne substrates at the propargylic positions. Direct nitrene $\mathrm{C}-\mathrm{H}$ insertion reactions represent an attractive alternative strategy to make propargyl amines from simple alkynes $;{ }^{6}$ however, selective $\mathrm{C}-\mathrm{H}$ amination of these substrates is extremely challenging. On the one hand, the highly reactive nitrene species are usually undiscriminating toward different functionalities (e.g., the triple bonds of alkynes are known to react with nitrenes ${ }^{7}$ ) and $\mathrm{C}-\mathrm{H}$ bonds, leading to low chemo- and regioselectivity and uncontrolled side reactions. On the other hand, the relatively small steric effect imposed by the alkynyl group can be a problem for enantiotopic differentiation in small-molecule catalysis. ${ }^{\mathrm{e}, 6 \mathrm{f}}$ Nonetheless, several catalytic systems based on cobalt, ${ }^{\mathrm{c}}, 6 \mathrm{~d}$ iridium, ${ }^{6 \mathrm{e}, 6 \mathrm{~h}}$ ruthenium $^{6 f, 6 \mathrm{~g}}$ or silver ${ }^{6 \mathrm{i}}$ have been developed for asymmetric intramolecular propargylic amination reactions since 2018 (Scheme 1b). To the best of our knowledge, however, there is only one example of an enantioselective intermolecular propargylic $\mathrm{C}\left(\mathrm{sp}^{3}\right)-\mathrm{H}$ amination in the literature, which used perfluoroaryl azide as the nitrene precursor. ${ }^{8}$

Since 2013, biocatalytic nitrene transformations have emerged as powerful tools for the construction of nitrogen-containing molecules. Several research groups have demonstrated that enzymatic nitrene $\mathrm{C}-\mathrm{H}$ insertion reactions can be achieved with excellent efficiency and selectivity on various substrates. ${ }^{9}$ In 2020 , we reported an unprecedented primary amination reaction of benzylic and allylic $\mathrm{C}-\mathrm{H}$ bonds using $\mathrm{P} 411$ enzymes (cytochromes $\mathrm{P} 450$ with serine in place of cysteine as their axial ligand). ${ }^{10}$ The remarkable ability of P411 enzymes to tame highly reactive unprotected nitrene species while also allowing exquisite stere-ocontrol demonstrates their catalytic potential for other challenging transformations. We therefore hypothesized that P411 enzymes could be suitable catalysts for propargylic amination. In this work, we show that an engineered P411 variant, namely PA-G8, derived from cytochrome $\mathrm{P} 450_{\mathrm{BM} 3}$ and improved by directed evolution, catalyzes an inter-molecular propargylic amination reaction (Scheme 1c) with excellent enantioselectivity and catalytic efficiency (up to $79 \%$ yield, >2000 TTN, and $82-96 \%$ ee).

We commenced this investigation of enzymatic propargylic amination by focusing on the reaction between 1-phenyl-butyne $\mathbf{1 a}$ and $O$-pivaloylhydroxylamine triflic acid ${ }^{11} \mathbf{2}$. The hydroxylamine-based nitrene precursor is more stable and safer to handle compared to the azide precursors used in our previous work. The expected primary amine product $\mathbf{3 a}$ is of biological interest ${ }^{12}$ and can be converted easily to other valuable compounds through downstream transformations. ${ }^{1}$ The reaction was first evaluated with a panel of hemoproteins, previously evolved for different nitrene and carbene transformations, ${ }^{13}$ in the form of whole 
Escherichia coli(E. coli) cell catalysts. Although most variants did not show detectable activity toward this reaction, a few of the P411 enzymes from the allylic primary amination lineage indeed showed promising initial activities. ${ }^{10}$ The best hit (P411-b4) among them could catalyze the standard reaction with $64 \%$ yield, albeit with negligible enantioselectivity ( $-1 \%$ ee). The heme domain of P411-b4 has four mutations (A78M, L263M, G268P, and $\mathrm{L} 437 \mathrm{G}$ ) with respect to our previously reported "E10" variant of $\mathrm{P}^{4} 50_{\mathrm{BM} 3}$ for benzylic $\mathrm{C}-\mathrm{H}$ tosylamidation, which has a solved crystal structure (PDB ID: 5UCW). ${ }^{9 b}$

Variant P411-b4 (named PA-G0 in this new lineage) was chosen as the parent for a directed evolution campaign (Figure 1a). Site-saturation mutagenesis (SSM) libraries were generated and screened by revisiting beneficial sites for previous P411-catalyzed transformations (see Table S1 and S2 in Supporting Information (SI) for all the targeted sites in directed evolution). To reduce the screening burden in SSM rounds, only variants which displayed more than $60 \%$ activity compared to the parent were assayed for enantioselectivity. Gratifyingly, by introducing a single mutation E267D, we obtained a new variant PA-G1, which could catalyze the model reaction with nearly quantitative yield and $28 \%$ ee. Seven additional rounds of SSM and screening generated the final variant PA-G8, which could perform propargylic amination in excellent yield and enantiocontrol (79\% analytical yield and 88\% ee). Mutations E267D, G437Q, and S438G, which reside on the flexible loop and the $a$-helix directly above the heme cofactor (Figure $1 \mathrm{~b}$ ), provide the most significant enantioselectivity boosts. All the mutations (E267D, N395C, G437Q, S72T, S438G, T269V, H266S, and A74K) were selected for enhancing enantioselectivity, even though some of them reduce the reaction yield (N395C, G437Q, S438G, and H266S).

After identifying the best variant PA-G8 for propargylic amination of the model substrate 1a, we next evaluated the enzyme's activity on an array of alkyne substrates (1b-1n) under the standard whole-cell reaction conditions (Figure 2a). In general, PA-G8 accepts many 1-aryl-2-alkyl alkynes, delivering the desired products with good to excellent enantioselectivity (82-96\% ee). Alkynes bearing longer alkyl chains could be transformed to the corresponding propargyl amines by PA-G8, albeit in lower yields ( $\mathbf{3 b}$ and $\mathbf{3 c}$ ). The absolute configurations of $\mathbf{3 b}$ and $\mathbf{3 c}$ were determined as $R$ (see section VIII in the SI for details). Interestingly, increased chain length correlated with improved enantioselectivities ( $91 \%$ and $96 \%$ ee for $\mathbf{3 b}$ and $\mathbf{3 c}$, respectively). Furthermore, aryl groups with various substitution patterns were well tolerated in this reaction, including substituents with different electronic properties at ortho-, meta-, and para-positions of the aromatic ring (3d-3i). Alkynes containing heteroaromatic rings were competent substrates as well (3j-3l). This is notable since many transition-metal-based catalytic systems are not compatible with heterocycles, especially pyridines, due to their tendency to deactivate transition-metal catalysts. ${ }^{14}$ Besides nitrene insertion into secondary $\mathrm{C}\left(\mathrm{sp}^{3}\right)-\mathrm{H}$ bonds, PA-G8 could also catalyze the amination reaction of primary and tertiary $\mathrm{C}-\mathrm{H}$ bonds $(\mathbf{3 m}$ and $\mathbf{3 n})$. Although the reaction yields were relatively low for some of the alkynes, ${ }^{15}$ we believe they can be improved through further optimization of these "propargylic aminases" (see Scheme S1 in SI for some preliminary efforts). We also tested PA-G8 with dialkyl alkynes, for example, 3-hexyne. Unfortunately, only trace yields were obtained with such substrates (see Figure S2 in SI for details). 
To demonstrate the synthetic utility of this biocatalytic platform, we performed the enzymatic reactions at 1-mmol scale with alkyne substrates 1a and 1d (Figure 2b). To our delight, propargyl amine 3a was obtained in 64\% isolated yield, $1150 \mathrm{TTN}$, and $88 \%$ ee. Similarly, product 3d was obtained in $64 \%$ yield, 1570 TTN, and $91 \%$ ee. After benzoyl protection, the optical rotation of amide $4 \mathbf{a}$ was measured as $+49.0(c=0.83$, in $\mathrm{CHCl}_{3}$ ), which is consistent with the reported value of $(R)-\mathbf{4 a}$, thus establishing the absolute configuration of $3 \mathbf{a}^{5 \mathrm{~b}}$

Finally, density functional theory (DFT) calculations with a truncated system were carried out to explore the nature of the nitrene insertion into propargylic $\mathrm{C}\left(\mathrm{sp}^{3}\right)-\mathrm{H}$ bond using model substrate 1a (see SI for computational details). DFT calculations describe the ironnitrenoid active species as a triplet ground state, in line with similar reported iron-nitrenoid species. ${ }^{16}$ Calculations indicate that nitrene insertion proceeds through a hydrogen atom transfer (HAT) step (TS1 $\Delta \mathrm{G}^{\ddagger}=14.7 \mathrm{kcal} \cdot \mathrm{mol}^{-1}$, in the triplet state) to initially form a propargyl radical intermediate, which then undergoes a radical rebound step (TS2 $\Delta \mathrm{G}^{\ddagger}=$ $8.2 \mathrm{kcal} \cdot \mathrm{mol}^{-1}$, in the triplet state) generating the final propargyl amine product (Figure 3 , and Figure S3 in the SI). This is similar to what was previously described for interand intramolecular nitrene $\mathrm{C}\left(\mathrm{sp}^{3}\right)-\mathrm{H}$ insertion based on sulfonamide and sulfamide $\mathrm{Fe}$ nitrenoids, ${ }^{16 a, 17}$ and acyl Fe-nitrenoids. ${ }^{16 \mathrm{~b}}$

The low energy barrier found for HAT TS1 $\left(\Delta \mathrm{G}^{*}=7.1 \mathrm{kcal} \cdot \mathrm{mol}^{-1}\right.$ from reactant complex, triplet state) reflects the enhanced stability of the propargyl radical being formed due to resonance and the high reactivity of the iron-nitrenoid. Higher activation barriers are found for the HAT step involving benzylic $\mathrm{C}\left(\mathrm{sp}^{3}\right)-\mathrm{H}$ bonds and Fe-acyl-nitrenoids. ${ }^{16 \mathrm{~b}} \mathrm{DFT}$ calculations also describe that protonation of the axial serine would slightly increase the HAT barrier, favoring the quintet electronic state over the triplet for the HAT and radical rebound steps (see SI discussion and Figures S3 and S4).

The radical rebound step is calculated to be much faster than that for the previously reported enantioconvergent amination of tertiary $\mathrm{C}\left(\mathrm{sp}^{3}\right)-\mathrm{H}$ bond (ca. $10 \mathrm{kcal} \cdot \mathrm{mol}^{-1}$ higher). ${ }^{16 a}$ The rapid capture of the propargyl radical suggests that the rebound process outcompetes radical reorientation and alkyl group rotation in the active site due to steric constraints. Consequently, the substrate (1a) and propargyl radical have similar orientations in the active site. Enantioselectivity of the amination process would be determined by the orientation of the propargyl radical during the rebound step. In effect, the selectivity of the amination process would be controlled by the binding pose of the substrate in the PA-G8 active site relative to the reactive iron-nitrenoid species. This is consistent with the improved enantioselectivities observed for substrates with longer alkyl chains (3b and $\mathbf{3 c}$, Figure 2), which will be geometrically more constrained in the binding pocket.

In summary, we established a biocatalytic platform for highly enantioselective nitrene propargylic $\mathrm{C}-\mathrm{H}$ insertion reactions to furnish a set of synthetically useful and biologically relevant propargyl amine products. This work represents the first example of an intermolecular propargylic $\mathrm{C}-\mathrm{H}$ amination reaction via a putative unsubstituted nitrene intermediate. Through eight iterative rounds of directed evolution, we identified a P411 variant PA-G8 which could catalyze the desired reaction in good efficiency and selectivity 
(up to $79 \%$ yield, >2000 TTN, and 96\% ee). In addition, PA-G8 could accept an array of different substituted alkyne substrates. DFT calculations provided mechanistic insights into the nitrene insertion, suggesting a key role of the enzyme active site in controlling the selectivity of the process by precisely positioning the substrate with respect to the Fe-nitrenoid species. Future work will be focused on engineering "propargylic aminases" for a broader scope of substrates, such as dialkyl alkynes, and investigating the origins of stereose-lectivity based on the new mutations introduced during the laboratory evolution. Further characterization of the nitrene intermediate would be valuable for generalizing this process as well. We envision that this enzymatic primary amination system can be applied to the preparation of bioactive chiral amines for synthetic chemistry and drug discovery.

\section{Supplementary Material}

Refer to Web version on PubMed Central for supplementary material.

\section{ACKNOWLEDGMENT}

This work is supported by the NSF Division of Molecular and Cellular Biosciences (grant 2016137 to F.H.A.), the National Institute of General Medical Sciences of the NIH (grant R01GM138740 to F.H.A., and R01GM124480 to K.N.H.), and the US Department of Energy, Office of Basic Energy Sciences (grant DE-SC0021141 to F.H.A.). M.G.-B acknowledges support from the Spanish Ministerio de Ciencia e Innovación (project PID2019-111300GAI00), and the Generalitat de Cata-lunya AGAUR (Beatriu de Pin0s H2020 MSCA-Cofund 2018-BP-00204 project). We thank David C. Miller, Anuvab Das, Kai Chen, Shilong Gao, Runze Mao, and Sabine Brinkmann-Chen for helpful discussions and comments on the manuscript. We thank Dr. S cott C. Virgil for his assistance with chiral-phase HPLC experiments. We further thank Mona Shahgholi for HRMS analysis.

\section{REFERENCES}

(1). Lauder K; Toscani A; Scalacci N; Castagnolo D Synthesis and reactivity of propargylamines in organic chemistry. Chem. Rev 2017, 117, 14091-14200. [PubMed: 29166000]

(2). Zindo FT; Joubert J; Malan SF Propargylamine as functional moiety in the design of multifunctional drugs for neurodegenerative disorders: MAO inhibition and beyond. Future Med. Chem 2015, 7, 609-629. [PubMed: 25921401]

(3). (a) Tardif J-C; L’Allier PL; Ibrahim R; Grégoire JC; Nozza A; Cossette M; Kouz S; Lavoie M-A; Paquin J; Brotz TM; Taub R; Pressacco J Treatment with 5-lipoxygenase inhibitor VIA-2291 (atreleuton) in patients with recent acute coronary syndrome. Circ. Cardiovasc. Imaging2010, 3, 298-307. [PubMed: 20190281] (b) Cossy J; Schmitt A; Cinquin C; Buisson D; Belotti D A very short, efficient and inexpensive synthesis of the prodrug form of SC-54701A a platelet aggregation inhibitor. Bioorg. Med. Chem. Lett 1997, 7, 1699-1700.

(4). Volkova Y; Baranin S; Zavarzin I $\mathrm{A}^{3}$ coupling reaction in the synthesis of heterocyclic compounds. Adv. Synth. Catal 2021, 363, 40-61.

(5). For selected examples, see:(a) Hattori G; Matsuzawa H; Miyake Y; Nishibayashi Y Coppercatalyzed asymmetric propargylic substitution reactions of propargylic acetates with amines. Angew. Chem. Int. Ed 2008, 47, 3781-3783.(b) Schmidt NG; Simon RC; Kroutil W Biocatalytic asymmetric synthesis of optically pure aromatic propargylic amines employing $\omega-$ transaminases. Adv. Synth Catal 2015, 357, 1815-1821.(c) Chen B-L; Wang B; Lin G-Q Highly diastereoselective addition of alkynylmagnesium chlorides to $N$-tert-butanesulfinyl aldimines: A practical and general access to chiral $a$-branched amines. J. Org. Chem 2010, 75, 941-944. [PubMed: 20041724]

(6). For selected examples of nitrene propargylic C-H insertion, see:(a) Paradine SM; Griffin JR; Zhao J; Petronico AL; Miller SM; White MC A manganese catalyst for highly reactive yet chemoselective intramolecular $\mathrm{C}\left(s p^{3}\right)-\mathrm{H}$ amination. Nat. Chem 2015, 7 987-994. [PubMed: 26587714] (b) Lu H; Li C; Jiang H; Lizardi CL; Zhang XP Chemoselective amination of 
propargylic $\mathrm{C}\left(\mathrm{sp}^{3}\right)-\mathrm{H}$ bonds by cobalt(II)-based metalloradical catalysis. Angew. Chem. Int. Ed 2014, 53, 7028-7032.(c) Li C; Lang K; Lu H; Hu Y; Cui X; Wojtas L; Zhang XP Catalytic radical process for enantioselective amination of $\mathrm{C}\left(\mathrm{sp}^{3}\right)-\mathrm{H}$ bonds. Angew. Chem. Int. Ed 2018, 57, 16837-16841.(d) Lang K; Torker S; Wojtas L; Zhang XP Asymmetric induction and enantiodivergence in catalytic radical $\mathrm{C}-\mathrm{H}$ amination via enantiodifferentiative H-atom abstraction and stereoretentive radical substitution. J. Am. Chem. Soc 2019,141, 1238812396. [PubMed: 31280562] (e) Park Y; Chang S Asymmetric formation of $\gamma$-lactams via C-H amidation enabled by chiral hydrogen-bond-donor catalysts. Nat. Catal 2019, 2, 219-227.(f) Xing Q; Chan C-M; Yeung Y-W; Yu W-Y Ruthenium(II)-catalyzed enantioselective $\gamma$-lactams formation by intramolecular C-H amidation of 1,4,2-dioxazol-5-ones. J. Am. Chem. Soc 2019, 141, 3849-3853. [PubMed: 30785737] (g) Zhou Z; Chen S; Hong Y; Winterling E; Tan Y; Hemming M; Harms K; Houk KN; Meggers E Non- $C_{2}$-symmetric chiral-at-ruthenium catalyst for highly efficient enantioselective intramolecular $\mathrm{C}\left(\mathrm{sp}^{3}\right)-\mathrm{H}$ amidation. J. Am. Chem. Soc 2019, 141, 19048-19057. [PubMed: 31751132] (h) Wang H; Park Y; Bai Z ; Chang S; He G; Chen $\mathrm{G}$ Iridium-catalyzed enantioselective $\mathrm{C}\left(\mathrm{sp}^{3}\right)-\mathrm{H}$ amidation controlled by attractive noncovalent interactions. J. Am. Chem. Soc 2019, 141, 7194-7201. [PubMed: 30978019] (i) Ju M; Zerull EE; Roberts JM; Huang M; Guzei IA; Schomaker JM Silver-catalyzed enantioselective propargylic C-H bond amination through rational ligand design. J. Am. Chem. Soc 2020, 142, 12930-12936. [PubMed: 32659081]

(7). (a) Thornton AR; Blakey SB Catalytic metallonitrene/alkyne metathesis: A powerful cascade process for the synthesis of nitrogen-containing molecules. J. Am. Chem. Soc 2008,130, 50205021. [PubMed: 18355007] (b) Lai X; Liu J-B; Wang Y-C; Qiu G Iron-catalyzed intramolecular acyl nitrene/alkyne metalation for the synthesis ofpyrrolo[2,1-a]isoindol-5-ones. Chem. Commun 2021, 57, 2077-2080.

(8). Jin L-M; Xu P; Xie J; Zhang XP Enantioselective intermolecular radical C-H amination. J. Am. Chem. Soc 2020, 142, 20828-20836. [PubMed: 33238707] There is an example of intermolecular propargylic $\mathrm{C}-\mathrm{H}$ amination using a chiral nitrene precursor to achieve diastereoselective control, see:Lebel H; Trudel C; Spitz C Stereoselective intermolecular C-H amination reactions. Chem. Commun 2012, 48, 7799-7801.

(9). For a review, see:(a) Liu Z; Arnold FH New-to-nature chemistry from old protein machinery: Carbene and nitrene transferases. Curr. Opin. Biotechnol 2021, 69, 43-51. [PubMed: 33370622] For selected examples:(b) Prier CK; Zhang RK; Buller AR; Brinkmann-Chen S; Arnold FH Enantioselective, intermolecular benzylic $\mathrm{C}-\mathrm{H}$ amination catalysed by an engineered iron-haem enzyme. Nat. Chem 2017, 9, 629-634. [PubMed: 28644476] (c) Singh R; Bordeaux M; Fasan R $\mathrm{P} 450$-catalyzed intramolecular $\mathrm{sp}^{3} \mathrm{C}-\mathrm{H}$ amination with arylsulfonyl azide substrates. ACS Catal. 2014, 4, 546-552. [PubMed: 24634794] (d) Dydio P; Key HM; Hayashi H; Clark DS; Hartwig JF Chemoselective, enzymatic $\mathrm{C}-\mathrm{H}$ bond amination catalyzed by a cytochrome $\mathrm{P} 450$ containing an Ir(Me)-PIX cofactor. J. Am. Chem. Soc 2017,139, 1750-1753. [PubMed: 28080030]

(10). Jia Z-J; Gao S; Arnold FH Enzymatic primary amination of benzylic and allylic C( $\left.\mathrm{sp}^{3}\right)-\mathrm{H}$ bonds. J Am. Chem. Soc 2020, 142, 10279-10283. [PubMed: 32450692]

(11). Makai S; Falk E; Morandi B Preparation of $O$-pivaloyl hydroxylamine triflic acid. Org. Synth 2020, 97, 207-216.

(12). Simon DZ; Salvador RL; Champagne G Acetylenics. 1. Aromatic amines containing the acetylenic triple bond.J. Med. Chem 1970, 13, 1249-1250.

(13). Yang Y; Arnold FH Navigating the unnatural reaction space: Directed evolution of heme proteins for selective carbene and nitrene transfer. Acc. Chem. Res 2021, 54, 1209-1225. [PubMed: 33491448]

(14). (a) L'Argentiere PC; Fígoli NS Selective hydrogenation of styrene. II. Poisoning of $\mathrm{Pd} / \mathrm{Al}_{2} \mathrm{O}_{3}$ by thiophene and pyridine. J. Chem. Technol. Biotechnol 1990, 48, 361-368.(b) Temel B; Tuxen AK; Kibsgaard J; Topsøe N-Y; Hinnemann B; Knudsen KG; Topsøe H; Lauritsen $\mathrm{JV}$; Besenbacher F Atomic-scale insight into the origin of pyridine inhibition of $\mathrm{MoS}_{2}$-based hydrotreating catalysts. J. Catal 2010,271, 280-289.

(15). For low-yielding examples, we only observed remaining alkyne substrates. No side products were detected.

(16). (a) Yang Y; Cho I; Qi X; Liu P; Arnold FH An enzymatic platform for the asymmetric amination of primary, secondary and tertiary $\mathrm{C}\left(s p^{3}\right)-\mathrm{H}$ bonds. Nat. Chem 2019, 11, 987-993. [PubMed: 
31611634] (b) Athavale SV; Gao S; Liu Z; Mallojjala SC; Hirschi JS; Arnold FH Biocatalytic, intermolecular $\mathrm{C}-\mathrm{H}$ bond functionalization for the synthesis of enantioenriched amides. Angew. Chem. Int. Ed 2021, 60, 24864-24869.

(17). Wang J; Gao H; Yang L; Gao YQ Role of engineered iron-haem enzyme in reactivity and stereoselectivity of intermolecular benzylic C-H bond amination. ACS Catal. 2020, 10, 53185327. 


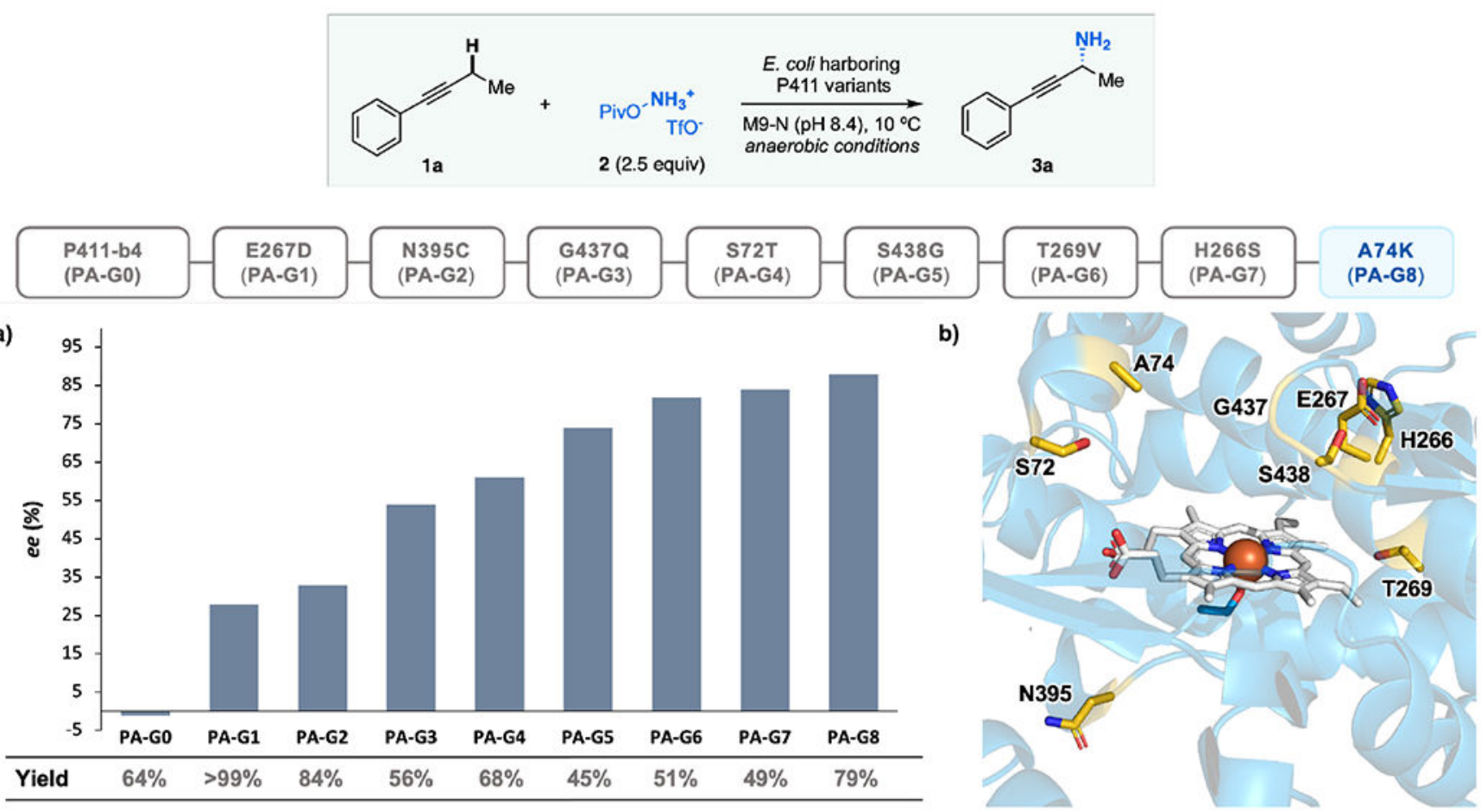

Figure 1.

Directed evolution for enantioselective propargylic amination. a) Evolutionary trajectory of PA-G8 for the synthesis of propargyl amine 3a. PA-G8 was evolved through eight rounds of SSM and screening starting from PA-G0. Indicated mutations are relative to PA-G0. The experiments were performed using $E$. coli $\left(\mathrm{OD}_{600}=20\right)$ that expressed $\mathrm{P} 411$ enzymes with $2 \mathrm{mM}$ substrate $1 \mathrm{a}$ and $5 \mathrm{mM}$ substrate 2 in $\mathrm{M} 9-\mathrm{N}$ buffer $(\mathrm{pH}=8.4)$ at $10{ }^{\circ} \mathrm{C}$ under anaerobic conditions. Performing reactions at $10{ }^{\circ} \mathrm{C}$ was found to give higher yields compared to running them at room temperature. Yields were quantified by LC-MS based on the calibration curve of 3a. Enantioselectivities were measured by HPLC on a chiral phase after benzoyl protection. See SI for details. b) The mutated residues (S72, A74, H266, E267, T269, N395, G437, and S438) are highlighted in the active site of P411 variant E10 (PDB ID: 5UCW). 


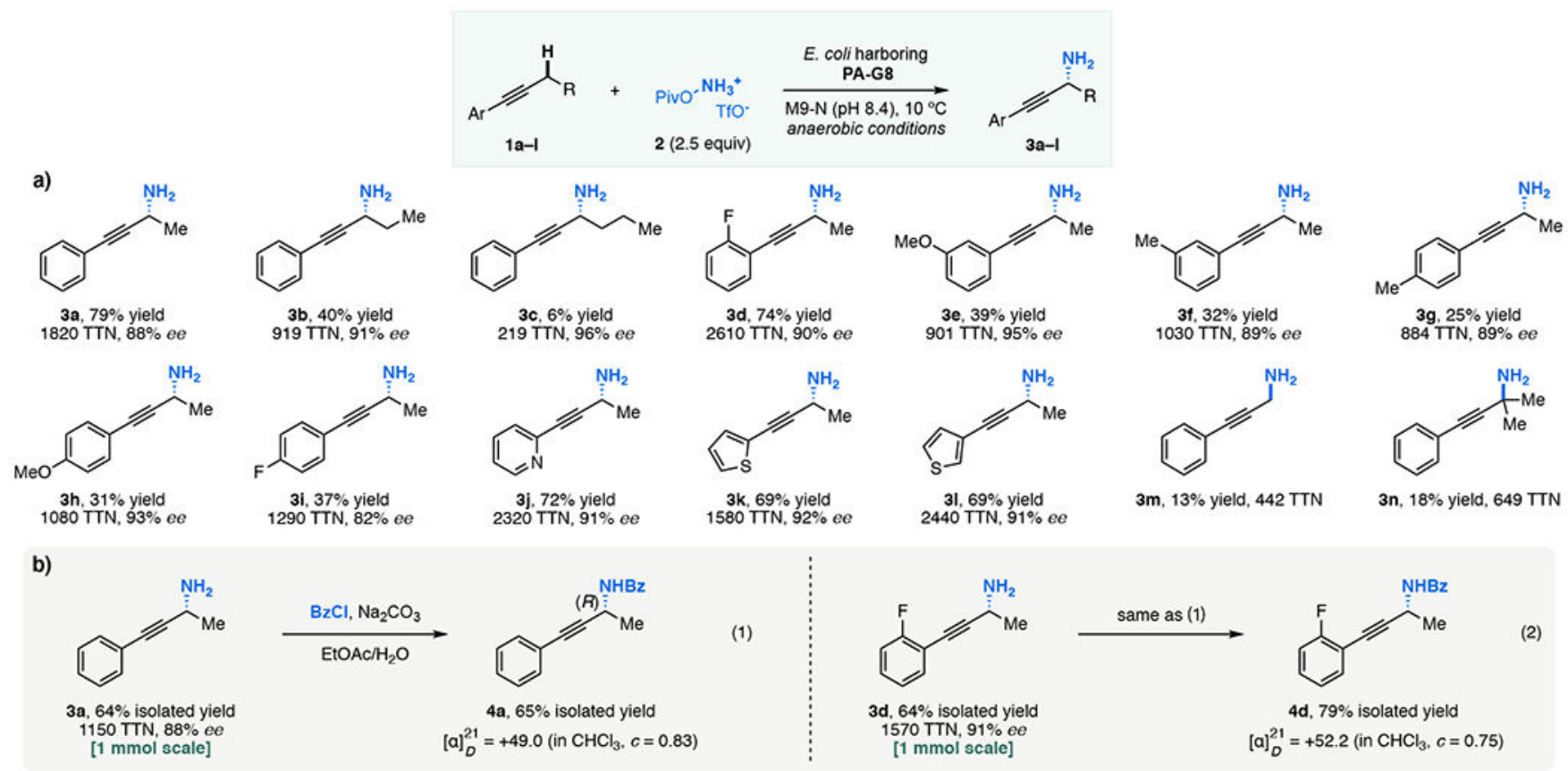

Figure 2.

a) Substrate scope of enantioselective propargylic amination. The experiments were performed at analytical scale using E. coli $\left(\mathrm{OD}_{600}=20\right)$ that expressed the PA-G8 enzyme with $2 \mathrm{mM}$ substrate (1a-l) and $5 \mathrm{mM}$ substrate $\mathbf{2}$ in $\mathrm{M} 9-\mathrm{N}$ buffer $(\mathrm{pH}=8.4)$ at $10{ }^{\circ} \mathrm{C}$ under anaerobic conditions. Yields were quantified by LC-MS based on the calibration curves of the corresponding reference products. Enantioselectivities were measured by HPLC on a chiral phase after benzoyl protection of the propargyl amine products. See SI for details. b) Preparative-scale synthesis and product derivatization for the determination of absolute stereochemistry. Chiral amides $\mathbf{4 a}$ and $\mathbf{4 d}$ were obtained from benzoyl protection of amines 3a and 3d. Compound $\mathbf{4 a}$ was used to determine the absolute stereochemistry by comparing the optical rotation with the reported value of $(R)-\mathbf{4 a} .^{5 b}$ 


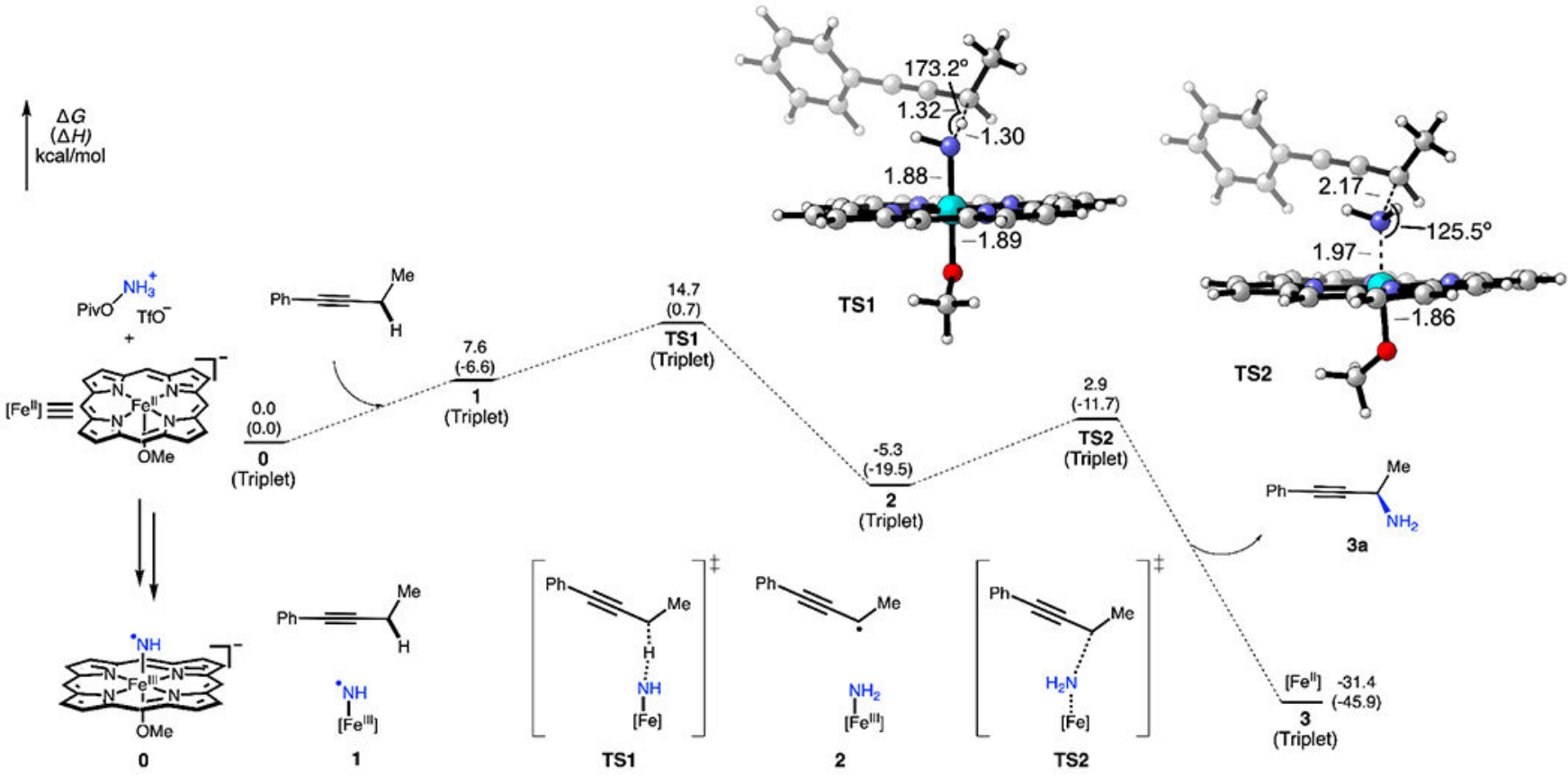

Figure 3.

DFT computed free energy profile for the iron(II)-porphyrin catalyzed propargylic $\mathrm{C}\left(\mathrm{sp}^{3}\right)-\mathrm{H}$ amination using a truncated computational model and substrate 1a. Gibbs free energies are obtained at the B3LYP-D3(BJ)/Def2TZVP/SMD( $\varepsilon=4) / / B 3 L Y P-D 3(B J) / 6-31 G(d)-S D D(F e)$ level of theory, and are given in $\mathrm{kcal} \cdot \mathrm{mol}^{-1}$. Key distances and angles are given in $\AA$ and degrees, respectively. 
a) Selected bioactive molecules containing propargyl amine moiety:<smiles>NC(=O)N(O)[CH]C#Cc1ccc(Cc2ccc(F)cc2)s1</smiles>

atreleuton

Treatment of atherosclerosis and coronary artery disease.<smiles>N=C(N)c1ccc(NC(=O)CCC(=O)NC(C#CCl)CC(=O)O)cc1</smiles>

SC-54701

A platelet aggregation inhibitor.

b) Previous work:

Examples of enantioselective propargylic $\mathrm{C}\left(\mathrm{sp}^{3}\right)-\mathrm{H}$ amination are rare.

Only one enantioselective intermolecular example.

Intramolecular examples<smiles>[R]C#C[C@H]1C[C@@H](CBr)NS1(=O)=O</smiles>

cat. Co

Zhang 2018-2019<smiles>[R]C#CC1CCC(=O)N1</smiles>

cat. Ir or Ru Chang, Yu, Meggers, Chen \& He 2019<smiles>[R]C#C[C@@H]1CCOC(=O)N1</smiles>

cat. $\mathrm{Ag}$

Schomaker 2020

Zhang, 2020<smiles>C1CCCCC1</smiles><smiles>[Al]</smiles>

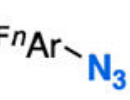<smiles>O=C(OCc1ccccc1)OCc1ccccc1</smiles><smiles>COC(=O)C#CC([Al])NC(C)C</smiles>

c) This work:
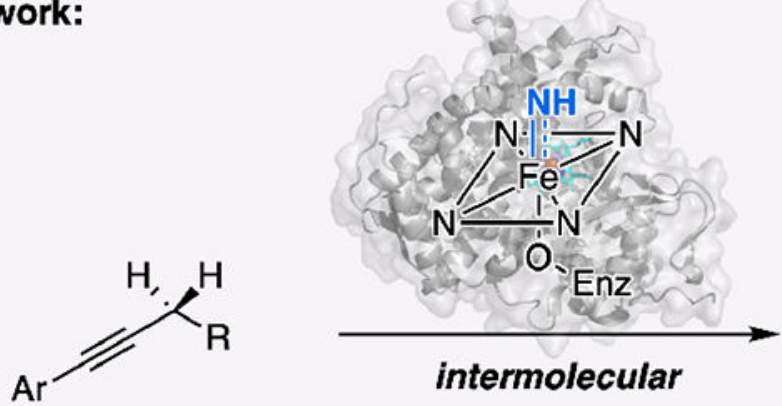

Scheme 1.

Background and Project Synopsis 